\title{
Memória organizacional e construção de identidade local: uma análise da mobilização e organização social no Conjunto Palmeira
}

\section{Organizational memory and construction of local identity: an analysis of social mobilization and organization in the Conjunto Palmeira, Brasil}

\author{
Bruno Chaves Correia-Lima \\ Mestrado em Administração e Controladoria pela Universidade Federal do Ceará (UFC). Doutorando em Administração pela Universidade Federal da Bahia. \\ brunoccl@hotmail.com
}

http://lattes.cnpq.br/8579383288595514

Ariadne Scalfoni Rigo

Doutorado em Administração pela Universidade Federal da Bahia (UFBA). Professora da Escola de Administração da UFBA e do Programa de Pós Graduação em Administração (NPGA).

ariadnescalfoni@gmail.com

http://lattes.cnpq.br/2648340817180242

Maria Elisabete Pereira dos Santos

Doutorado em Ciências Sociais pela Universidade Estadual de Campinas. Professora Adjunta III da Escola de Administração da UFBA

betesantos@ufba.br

http://lattes.cnpq.br/0544260389945180

Resumo: Este trabalho objetiva analisar mecanismos pelos quais a memória organizacional influencia a construção e o fortalecimento da memória e da identidade do Conjunto Palmeira (Fortaleza, Ceará), caracterizado por uma história identitária de mobilização social e economia solidária. Pesquisa qualitativa, documental e de campo, em que foram analisados 53 documentos da memória de três organizações sociais partícipes da história local: associação do bairro, Banco Palmas e Instituto Palmas. Foram realizadas três entrevistas com representantes das organizações sociais e da fundação municipal de assistência social. Os resultados apresentam diferenciações entre mecanismos de memória organizacional, utilizados para influenciar o ambiente externo daqueles que objetivam contribuir para gestão intraorganizacional. Livros, vídeos, cartilhas, maquetes, atas de reuniões, cordéis, roteiros de peça de teatro, fotonovelas, se configuram como mecanismos utilizados para estimular o envolvimento da comunidade em projetos comuns. Os efeitos da utilização dessa memória estão relacionados a processos contínuos de aprendizagem e de construção da identidade local.

Palavras-chave: Memória Organizacional, Memória Social, Identidade, Economia Solidária, Mobilização Social.

Abstract: This work aims to analyze the Organizational Memory mechanisms used to influence the construction of the identification of the Conjunto Palmeira (Fortaleza, Ceará), characterized by an historical identity of social mobilization and solidarity economy. This work was developed with qualitative research, documentary and field in which analyzed 53 documents from memory three participants social organizations of local history: neighborhood association, the Palmas Bank and the Palmas Institute. Three interviews with representatives of social organizations and municipal foundation of social assistance were made. The results show differences between organizational memory mechanisms used to influence the external environment of those who aim to contribute to intraorganizational management. Books, videos, brochures, models, meeting minutes, "cordéis", stage play scripts, "fotonovelas" are configured as mechanisms used to encourage community involvement in joint projects. The effects of the use of this memory are related to continuous learning processes and construction of the identity of the site.

Keywords: Organizational Memory, Social Memory, Identity, Solidarity Economy, Social Mobilization.

Texto completo em português: http://www.apgs.ufv.br Full text in Portuguese: http://www.apgs.ufv.br

\section{Introdução}

A compreensão de como as organizações registram e recuperam conhecimentos e vivências tem se configurado como uma agenda de pesquisa recorrente nos Estudos Organizacionais a partir do construto Memória Organizacional, que se vincula à Gestão do Conhecimento e à Aprendizagem Organizacional como etapa de seu processo (Nonaka \& Toyama, 2008; Santos, Maldonado, Santos \& Steil, 2012; Freitas, Tosta, Helou Filho \& Silva, 2012).

Entretanto, os estudos sobre Memória Organizacional, de acordo com Rowlinson, Booth, Clark, Delahaye e Procter (2010),
Costa e Saraiva (2011) e Zancaro, Erpen, Santos, Stell e Todesco (2012), se limitam a contextos empresariais cujo objetivo é sua utilidade gerencial interna para tomadas de decisões estratégicas que possibilitem maior competitividade. Por essa abordagem, ferramentas computacionais, sistemas de relatórios, e-mails, documentos de conferências e reuniões, entre outros, se configuram como recipientes de armazenamentos que são utilizados como mecanismos para favorecer objetivos da organização: evitar perdas de conhecimentos de funcionários, explorar e reutilizar experiências passadas, melhorar a circulação 
de informações (Nilakanta et al., 2006; Rowlinson, Booth, Clark, Delahaye \& Procter, 2010).

Entretanto, a memória organizacional deve permitir responder questões tanto sobre a organização como sobre o ambiente onde está inserida (Simão, 2010). Além do ambiente interno, o conhecimento organizacional se relaciona diretamente com atores do ambiente externo, tais como clientes, cidadãos e comunidade (Choo, 2006), vinculando-se assim também com memória e identidade social (Rowlinson et al., 2010).

A memória social exerce papel fundamental para a vida cultural e a definição da identidade de um grupo de pessoas (Levandoski, Tonini \& Barreto, 2012). Essa memória é formada a partir da acumulação de eventos ao longo do processo histórico local, alimentando a memória individual no interior dos grupos, possibilitando a formação de uma identidade social (Halbwachs, 1990). A identidade, então, vem de uma construção e reconstrução social histórica, valorizando a aceitação ou rejeição coletiva de signos e significados (Geertz, 1989; Hall, 2003; Levandoski, Tonini \& Barreto, 2012) e incide em uma teia de relações existentes, imprimindo nela consequências imediatas (Souza \& Carrieri, 2012). Em situações que esses significados distinguem um lugar ou uma região por um arranjo de variáveis, pode-se explicar uma periodização e, por vezes, uma construção de identidade local (Santos, 1997).

Contudo, mediante o enfoque sobre aspectos internos de gestão, as pesquisas que tratam de memória organizacional no campo dos Estudos Organizacionais acabam negligenciando contextos sociais mais amplos em que a organização está inserida. Ou seja, ignoram a importância da memória organizacional para a memória coletiva e social (Rowlinson et al., 2010; Costa \& Saraiva, 2011).

Portanto, a literatura sobre Memória Organizacional apresenta diversos estudos, voltados ao contexto interno de gestão, que indicam os mecanismos utilizados para registrar, armazenar, resgatar conhecimentos visando competitividade e melhorias de desempenho. Entretanto, esse campo de pesquisa apresenta lacunas quanto: à identificação de mecanismos de memória organizacional para exercer influência sobre o contexto social externo; à análise dos efeitos da utilização dessa memória organizacional sobre atores externos. Para contribuir com 0 preenchimento dessas lacunas, este artigo apresenta e analisa elementos de um caso em que a memória de organizações sociais exerce influências para além das funções gerenciais internas, impactando também na memória e na identidade social da comunidade circundante.

O ambiente trabalhado neste estudo de caso é uma das principais referências de experiência de economia solidária e desenvolvimento local no Brasil. $O$ bairro Conjunto Palmeira (Fortaleza, Estado do Ceará) se configura como um local cuja identidade é caracterizada pela mobilização social e solidariedade econômica exercida por seus moradores há quase quatro décadas. Os protagonistas e as organizações sociais locais foram atores fundamentais na construção da identidade desse bairro.
Neste trabalho, são focadas três destas organizações locais: a Associação dos Moradores do Conjunto Palmeira (ASMOCONP), o Banco Palmas e o Instituto Palmas. A ASMOCONP foi criada em 1981 para organizar e mobilizar a comunidade que buscava a melhoria das suas condições de vida. Em 1997, a ASMOCONP criou o Banco Palmas como estratégia solidária para a então prioridade do bairro, o desenvolvimento econômico. E, em 2003, a ASMOCONP criou o Instituto Palmas, que hoje é uma Sociedade Civil de Interesse Público (OSCIP), cuja função é realizar a difusão tecnológica do Banco Palmas, contribuindo na criação de outros bancos comunitários no Brasil e integrando-os em redes (Instituto Palmas, 2009).

Este artigo tem como objetivo analisar mecanismos pelos quais a memória organizacional influencia a construção e o fortalecimento da memória e da identidade local, no caso, do Conjunto Palmeira. Já sendo conhecidos mecanismos e efeitos relacionados à gestão intraorganizacional, a relevância deste estudo consiste na contribuição para a literatura de Memória Organizacional ao identificar os mecanismos de memória utilizados para exercer influência sobre o contexto externo e analisar seus efeitos sobre a comunidade circundante.

Este estudo de natureza qualitativa se deu a partir de pesquisas bibliográfica, documental e de campo. Por meio da técnica análise de conteúdo, 53 diferentes documentos organizacionais foram analisados à luz das referências teóricas dos construtos memória organizacional e identidade. Também foram realizadas três entrevistas semiestruturadas com pessoas chave das organizações sociais do bairro.

\section{Memória organizacional, memória social e construção de identidade}

O termo "memória", nas Ciências Sociais, originou-se sendo relacionado a estudos sobre relações sociais e aspectos culturais. Sendo assim, a ideia de memória organizacional não se distinguia de noções como as de memória coletiva e memória de grupo (Molina \& Valentin, 2011).

Stein (1995) define memória organizacional como função da persistência de características das organizações ao longo do tempo, indicando a existência de mecanismos capazes de reter informações e de recuperá-las para o presente através do sistema social. Para Simão (2010), a memória organizacional deve permitir responder questões tanto sobre a organização como também sobre seu ambiente. Isso porque, como explicita Choo (2006), além do ambiente interno o conhecimento organizacional se relaciona diretamente com atores do ambiente externo, tais como clientes, cidadãos entre outros.

Embora esses autores ressaltem o significado do ambiente social na memória organizacional, os estudos sobre o tema têm se limitado apenas a visões gerencialistas, que privilegiam a função utilitária da memória nas decisões empresariais e em modelos mecânicos processados em sistemas de informação, deixando à margem das discussões temas vinculados aos estudos de memória social, como a memória coletiva, a memória cultural, as 
comemorações ou rememorações sociais (Rowlinson et al., 2010; Costa \& Saraiva, 2011). A carência de pesquisas nesse sentido nos estudos organizacionais é indicada por Costa e Saraiva (2011) como algo sintomático de uma área que supervaloriza lógicas mercadológicas, modelos estrangeiros pré-concebidos e análises imediatistas sem olhares cuidadosos para o processo histórico.

Como memória social, Misztal (2003) define a representação do passado em um conjunto de ideias, saberes, práticas culturais, rituais e monumentos através do qual as pessoas expressam suas relações e atitudes sociais. São espaços e mecanismos que abrigam a memória social: bibliotecas, lendas folclóricas, álbum de fotografias, arquivos de jornais e televisões, livros históricos, calendários, livros de visitas, lápides, memoriais, aniversários, eventos comemorativos, exposições públicas de objetos históricos e arqueológicos. Muitas manifestações organizacionais estão presentes nessas formas de memória social (Rowlinson, et al., 2010).

A relação entre os construtos memória organizacional e memória social é valorizada por Rowlinson et al. (2010) ao enfatizarem que as organizações preservam o passado social também, por exemplo, através de uma variedade de documentos disponíveis publicamente, tais como relatórios anuais, comunicados à imprensa, sites, revistas e históricos organizacionais, bem como por meio de edificações, eventos, artefatos e produtos comemorativos, recordativos e decorativos.

Portanto, apresenta-se assim a possibilidade de influência mútua entre as memórias classificadas como organizacionais e sociais. Assim como a memória social recebe influência da memória organizacional, as organizações não são em si os únicos repositórios de seu passado, fazendo uso também de arquivos externos (Walsh \& Ungson, 1991; Rowlinson et al., 2010). E, para Rowlinson et al. (2010), tanto os estudos em memória organizacional têm demonstrado certa indiferença ao contexto social mais amplo, como os estudos de memória social têm ignorado a importância das organizações para a memória coletiva.

Como análise da memória organizacional, Rowlinson et al. (2010) consideram que se devem abordar as seguintes questões: - conteúdo da memória, que diz respeito à natureza do conhecimento; a forma da memória, relacionada ao suporte de armazenamento; o funcionamento da memória, relacionado ao sistema que gerencia o conhecimento.

No contexto de organizações sociais, uma das finalidades da memória organizacional é o fortalecimento associativo com atores sociais, configurando enlaces que podem apresentar, desde coerções, até genuínas colaborações e relações de solidariedade (Britton, 2005).

A memória se apresenta também como um dos elementos identitários essenciais. Decisões políticas sobre o que deve ser lembrado e o que deve ser esquecido configuram um contexto de revelação de instrumento de poder que permite desvelar componentes ideológicos presentes nas escolhas e a construção social do passado (Costa \& Saraiva, 2011). Desse modo, estudos interdisciplinares em várias partes do mundo admitem e ressaltam a importância da relação entre memória e identidade cultural (Erll \& Nünning, 2008).

Levandoski, Tonini e Barreto (2012) ressaltam a importância da memória coletiva como fundamento da revitalização da cultura e da definição da identidade de um grupo. A memória coletiva, segundo Halbwachs (1990), se forma a partir da acumulação de eventos ocorridos durante anos de história. A memória individual tem uma estrutura de natureza psicológica e nutre-se da memória coletiva, visto que todas as lembranças constituem-se no interior dos grupos, possibilitando, assim, o anúncio de identidade. Ao examinar o modo como os grupos constroem e desenvolvem sua identidade coletiva, Zerubavel (2012) ressalta o esforço de inclusão através da construção de uma memória comum, por parte de organizações e grupos, sendo esse processo um elemento legitimador da identidade construída.

Identidade social é uma formação entendida a partir da construção do autoconceito pela vinculação a grupos sociais, por meio da interação com esses diversos grupos (Pimentel \& Carrieri, 2011). É historicamente elaborada, atuando nas identidades pessoais como memória permanente atualizada por meio da autorreflexão, da interação, da afiliação, do simbolismo e do mundo social a partir da tríade: sujeito, sociedade e trabalho (Strauss, 1999).

A compreensão da expressão identidade passa pelo entendimento do seu caráter dinâmico, não sendo simplesmente um produto ou um objeto fixo (Donders, 2005). Para Castells (1999, p.23), identidade é a "fonte de significado e experiência de um povo". A construção da identidade é feita sempre com a integração entre elementos do presente e do passado, gerando continuidade. A construção da identidade é um fenômeno que se caracteriza por se produzir em referência aos outros, por pressupor critérios de aceitabilidade e credibilidade, além de se relacionar com interações sociais e simbólicas (Bonilha \& Sachuk, 2011).

Ressaltam-se nessa construção elementos fornecidos pela história, geografia, biologia, instituições produtivas e reprodutivas, pela memória coletiva e por fantasias pessoais, todos processados pelos indivíduos, grupos sociais e sociedades que reorganizam sua identificação simbólica a partir de tendências sociais, de projetos culturais enraizados na sua estrutura social e de sua visão de tempo e espaço (Castells, 1999).

Sendo assim, o processo de viver em coletividades inclui os processos produtivos e as práticas de organização social. Neste artigo, tomam-se esses dois constructos considerados caracterizadores (e interligados) da identidade social do Conjunto Palmeira (locus do estudo de caso em questão). As práticas de organização social são traduzidas no caso pelo processo de mobilização social nas constantes lutas por melhorias das condições de vida no lugar; e os processos produtivos (apesar de múltiplos) são aqui representados por uma importante iniciativa de organização produtiva do bairro. Esta organização produtiva a partir, principalmente, da iniciativa de um Empreendimento de Economia Solidária (o Banco Palmas) atrelada aos processos de mobilização social imprimiu ao bairro a identidade que hoje se 
estampa em slogans e muros na entrada do Conjunto Palmeira, conhecido como "O bairro da Economia Solidária".

\subsection{Mobilização social, economia solidária e suas relações com a identidade}

A mobilização social está associada ao engajamento de pessoas que, além de terem carências, interesses e problemas em comum, podem compartilhar valores e visão de mundo semelhantes (Henriques, Braga, Couto \& Silva, 2004). A mobilização social é um processo de desenvolvimento de condições materiais, psicossociais e políticas, que são necessárias para a constituição de ações coletivas. Esse processo de mobilização social se dá a partir do momento em que se inicia um processo de politização das relações sociais (Prado, 2002).

Braga, Henriques e Mafra (2007) ressaltam a importância da comunicação nas mobilizações sociais visando a participação de sujeitos ativos que buscam problematizar com outro para melhor compreender, explicar e transformar a realidade. Há, então, uma construção dialógica entre os públicos envolvidos no intuito de construir as bases para transformação e fomentar a discussão de cunho educativo (Cruz \& Silva, 2013).

Na visão de Prado (2002), a mobilização social se configura como um elemento central entre a existência de uma identidade social e a construção de uma identidade política. Essas identidades diferenciam-se essencialmente pela expressão ou não de antagonismos nas relações de subordinação. Prado (2002, p. 60) afirma que a identidade social se estabelece como "um conjunto de atribuições e referências da pertença grupal e social do indivíduo". Já a identidade política é "um conjunto temporário de significados que delimitam fronteiras na questão dos direitos sociais", em que determinados atores impedem outros da realização de suas demandas sociais, explicitando uma relação antagônica. De uma maneira mais ampla, a identidade política pode ser entendida como concepções da própria sociedade por parte de um grupo. Assim, o processo de mobilização social é capaz de constituir a identidade política que resulta necessariamente em mudança social (Prado, 2002).

A economia solidária é concebida como um modo de produção centrado na humanização nas relações de trabalho e norteado por valores de solidariedade, cooperação, democracia, sustentabilidade ambiental, sob forma coletiva e autogestionária, diferenciando-se assim da lógica econômica capitalista hegemônica (Singer \& Souza, 2002; Medeiros \& Cunha, 2012).

Existem duas dimensões que conformam a economia solidária: a luta pela renda, vinculada a uma economia popular orientada pela necessidade de satisfação material básica; e a luta por uma reprodução ampliada das condições de vida em sociedade que pode se denominar por luta por direitos sociais, implicando uma abertura de sua ação para um espaço público. Portanto, a extensão do fenômeno indica uma reconfiguração das relações entre o econômico, o social e o político (França Filho, 2004 e 2013). Nesse sentido, a prática da economia solidária se relaciona com os processos de construção de identidades pessoal, social e política, pois, para Beuron, Matos, Barros e Grohmann
(2011), a conceituação de identidade não pode ser dicotômica ao conceito de trabalho e de sociedade. Para os autores, a lógica capitalista de centralidade do trabalho na vida do homem, resumida como meio exclusivo de sobrevivência e criação de mais valia, gera um processo de negação do homem por si mesmo, despersonalizando-o e convertendo-o a mera mercadoria, acarretando sobressaltos à construção identitária pessoal e social. De modo análogo, Rocha-Pinto, Irigaray e Silva (2011) afirmam que, quando os arranjos de trabalho são orientados por uma racionalidade substantiva em detrimento da racionalidade instrumental, há o processo de conscientização do ser cooperativo, enquanto uma identidade.

Estudos realizados em diferentes contextos, tais como Pinto, Irigaray e Silva (2011), Gattai e Bernardes (2013) e Abreu, Lima, Silva e Cunha (2012), valorizam a importância de um agente externo como mediador e orientador no processo de fortalecimento de experiências norteadas pela cooperação e solidariedade. Esse agente organizacional - que pode ser vinculado a universidades, institutos, associações, organizações públicas ou privadas - exerce papel fomentador de recursos materiais e humanos que contribuem com a formação e sustentabilidade da experiência.

\section{0 caminho da pesquisa}

O presente estudo se caracteriza, quanto aos objetivos, como exploratório e descritivo, por se tratar de pesquisa que descreve informações sobre contribuições de memória organizacional para o ambiente externo à organização. Tal contexto dispõe de pouca informação nos Estudos Organizacionais, conforme destacado por Rowlinson et al. (2010) e Costa e Saraiva (2011), que afirmam que as pesquisas têm negligenciado contextos sociais mais amplos, sobrevalorizando visões internas, gerencialistas.

Trata-se de uma pesquisa qualitativa por possibilitar uma análise de maior amplitude da observação do fenômeno histórico, admitindo inferências do ambiente (Conjunto Palmeira) e das pessoas que dele participam. Tal uso se adequa, segundo Richardson (2008), a pesquisas que contemplam fatos do passado, análises de atitudes e valores, e funcionamento de estruturas sociais.

Quanto aos procedimentos, a pesquisa é bibliográfica por realizar a busca pelo estado da arte sobre os assuntos abordados, documental por analisar 53 documentos institucionais e, de campo devido à coleta de dados junto a representantes organizacionais. Rowlinson, Hassard e Decker (2014) valorizam a contribuição de pesquisas documentais em trabalhos que relacionem contextos históricos com estudos organizacionais.

A pesquisa documental deste estudo foi realizada mediante vasta busca no acervo documental das organizações sociais ASMOCONP, Banco Palmas e Instituto Palmas. Tal conteúdo documental possibilitou a compreensão da formação da identidade do lugar, bem como a análise dos mecanismos de memória organizacional que influenciaram a continuidade dessa identidade construída no transcorrer das quatro últimas décadas. Foram 
analisados 53 documentos selecionados por critério de frequência de utilização e, em seguida, classificados conforme sua materialidade. São 14 relatórios de gestão organizacional, 13 fotos ou fotonovelas, 7 livros, 5 cartilhas, 3 DVD`s, 3 unidades de papel moeda/cartão de crédito e 8 unidades de outros materiais, tais como panfletos, cordéis, roteiros, jornal comunitário, $C D$ e site.

Foram realizadas também três entrevistas cujos roteiros foram semiestruturados. Os entrevistados são atores-chave participantes do processo de construção do Conjunto Palmeira: o coordenador e representante do Instituto e Banco Palmas; a diretora executiva da ASMOCONP e também moradora do bairro desde a década de 1970; e uma representante da Fundação do Serviço Social de Fortaleza (FSSF). Ressalta-se que tal fundação foi designada pela Prefeitura Municipal de Fortaleza, em 1972, para conceder assistência social aos então novos habitantes do lugar que viria se tornar o Conjunto Palmeira.

Os 53 documentos e as três entrevistas tiveram seus conteúdos analisados a partir da identificação de elementos que caracterizassem o processo de construção da identidade do Conjunto Palmeira: a identificação dos mecanismos de memória das organizações sociais para continuidade da identidade do Conjunto; e a análise dos efeitos dessa memória sobre o ambiente externo, especialmente a comunidade circundante.

\section{Discussão dos Resultados}

4.1 Processos de mobilização social, organização produtiva e de construção da identidade do Conjunto Palmeira

O Conjunto Palmeira é um local situado na periferia de Fortaleza, Ceará. A presente análise é iniciada considerando o contexto de cidade (Fortaleza) no qual o Conjunto está inserido, pois desde a sua formação até os presentes dias, é percebido, no lugar, os reflexos dos problemas sociais da capital cearense.

Na década de 1970, período de ponto de partida do Conjunto Palmeira, Fortaleza avançava seu processo de urbanização e, nessas circunstâncias, seus governantes, assim como os de outras várias cidades brasileiras, promoviam uma "assepsia" urbana com o deslocamento dos pobres para a periferia da cidade (Melo Neto \& Magalhães, 2003a). Tal fato é explicado por Oliveira (2001) como uma tendência de concentração inerente ao processo capitalista no nível macro. Essa tendência se expressa em uma espécie de hélice de duas pás, enroscando a concentração econômica com a concentração espacial. Investimentos públicos levam a valorizações de áreas que passam a ser consideradas nobres, enquanto as áreas abandonadas se transformam em residenciais de baixíssimo nível (Oliveira, 2001).

Em 1972, 1,5 mil famílias foram retiradas de áreas em processo de valorização econômica e também de áreas ribeirinhas de recorrentes alagamentos e transferidas pela prefeitura para um terreno baldio de uma área pantanosa na periferia de Fortaleza. "Tinham muitas crianças, idosos, muita gente que só tinha a roupa do corpo depois de perder tudo nas enchentes... E foram transferidos todos para esse terreno" (Entrevista, representante da FSSF, janeiro de 2015). Esse lugar, que viria a ser o Conjunto Palmeira, era um grande alagado distante do Centro de Fortaleza, que não tinha fornecimento de luz, água ou qualquer condição de urbanização, assim como relata E-03, então colaboradora da Fundação do Serviço Social de Fortaleza (FSSF): "Era só um terreno, no meio do nada, em que a prefeitura desmatou e se comprometeu a providenciar melhorias. Mas do jeito que estava lá não dava para viver. Como eles iriam se deslocar para o trabalho? Não tinha nada!" (Entrevista, representante da FSSF, janeiro de 2015). Depoimentos de moradores registrados no livro Memórias de Nossas Lutas confirmam o difícil contexto inicial: "Pegavam a gente com as coisas e tudo, jogavam numa caçamba e despejavam no Palmeira, que era lama e mato só"; "Não havia condições de vida humana". Após grande movimentação de terra e derrubamento de carnaubeiras - daí o nome Palmeira espontaneamente, os moradores foram construindo seus barracos de papelão, plástico, palha e outros materiais possíveis. Em seguida, a Fundação do Serviço Social de Fortaleza (FSSF) demarcou lotes, comprados pelas famílias, e cedeu material para construção de um cômodo (Melo Neto \& Magalhães, 2003a; Melo Neto \& Magalhães, 2003b; ASMOCONP, 2011).

A partir de 1977 aconteceu um forte processo de organização e mobilização social no Palmeira. "São travadas grandes lutas pela conquista de serviços básicos para o bairro, principalmente pela rede de água tratada e pela drenagem" (Melo Neto \& Magalhães, 2003b). Os fatos ocorridos no Conjunto Palmeira caracterizam mobilizações sociais, em consonância com a discussão teórica apresentada (Henriques, Braga, Couto \& Silva, 2004; Prado, 2002), a partir de necessidades comuns, em que moradores unidos geraram uma sequência de movimentações (Quadro 1) que caracterizaram uma identidade de mobilização social ao Conjunto.

Destas mobilizações sociais destacam-se os embates políticos ocorridos em 1988 pelo abastecimento de água e o ocorrido em 2003 junto ao BACEN. No primeiro, houve um claro enfretamento com o poder público, representado pelo Governo do Estado do Ceará, ao ameaçar o bem-estar da cidade de Fortaleza pela possibilidade de explodir a adutora que abastecia a capital, caso a rede de abastecimento de água não fosse implantada imediatamente no Conjunto Palmeira. $\mathrm{Na}$ análise documental foram identificados relatos de lideranças locais que narram este e outros episódios.

[...] nem tínhamos explosivos e, tampouco sabíamos com exatidão onde passava a tubulação, contudo era uma queda de braço [... Começamos a simular a perfuração do solo até ser percebido pelos policiais que avançaram sobre nós e fecharam o cerco. Dissemos: se algo acontecer com nós, explodiremos tudo, a água invadirá toda área e morreremos juntos. [...] um tenente pediu calma e disse que iria falar com seu comandante. [...] Voltou informou que o governador havia se comprometido a iniciar imediatamente a distribuição da água para o Conjunto. As tropas se dispersaram e ficamos a comemorar mais uma vitória (Melo Neto \& Magalhães, 2003a, p. 13). 
Quadro 1 - Mobilizações sociais na história do Conjunto Palmeira

\begin{tabular}{|c|c|c|}
\hline ANO & MOBILIZAÇÃO & DESCRIÇÃO \\
\hline 1977 & $\begin{array}{l}\text { Emergência Comunitária do } \\
\text { Conjunto Palmeira }\end{array}$ & $\begin{array}{l}\text { Conforme liderança local, “...tínhamos uma rural (veículo) para transporte de doentes...havia } \\
600 \text { sócios... Com o tempo a Emergência Comunitária se transforma em Funerária } \\
\text { Comunitária”. }\end{array}$ \\
\hline 1978 & $\begin{array}{l}\text { Construção e vivência da } \\
\text { igreja }\end{array}$ & $\begin{array}{l}\text { Construída a igreja católica, com a ajuda dos padres da Barra do Ceará (bairro de Fortaleza). } \\
\text { Formadas Comunidade Eclesiais de Base (CEBS) e Juventude Cristã do Palmeira } \\
\text { (JUCRISPA). }\end{array}$ \\
\hline 1978 & Casa de Parto & Casa de Parto foi construída por iniciativa dos representantes de quadra \\
\hline 1978 & $\begin{array}{l}\text { Escola, Centro Social e Posto } \\
\text { de Saúde }\end{array}$ & $\begin{array}{l}\text { Conquistas importantes: a construção da Escola de } 1^{\circ} \text { Grau A. Barbosa, o Centro Social } \\
\text { Urbano (CSU) e o Posto de Saúde Pedro Sampaio. }\end{array}$ \\
\hline 1981 & ASMOCONP & $\begin{array}{l}\text { Consolidação da Associação dos Moradores do Conjunto Palmeira (ASMOCONP) com } \\
\text { elaboração e registro do estatuto em 02/02/1981, seguida de campanha para construção da } \\
\text { sede. }\end{array}$ \\
\hline 1985 & $\begin{array}{l}\text { Manutenção em programa de } \\
\text { assistência federal, por meio } \\
\text { do município. }\end{array}$ & $\begin{array}{l}\text { Os líderes da ASMOCONP mobilizaram o bairro para pressionar a Prefeitura para extensão do } \\
\text { benefício das cestas básica aos cadastrados nos postos de saúde municipais. No paço } \\
\text { municipal, os moradores do Palmeira desocuparam a sede somente após solução do } \\
\text { problema. }\end{array}$ \\
\hline 1987 & Memória de Nossas Lutas & $\begin{array}{l}\text { Participação no Programa Memórias de Nossas Lutas, da ONG francesa Gret, com parceiras. } \\
\text { Líderes comunitários foram capacitados para resgatar e registrar as memórias do bairro por } \\
\text { meio de pesquisa-ação. }\end{array}$ \\
\hline 1988 & $\begin{array}{l}\text { Luta pelo abastecimento de } \\
\text { água }\end{array}$ & $\begin{array}{l}\text { Intensa mobilização popular com duas visitas à companhia de água, concentração em frente à } \\
\text { sede do Governo Estadual e ameaça de explodir a adutora que abastecia Fortaleza, se não } \\
\text { fosse construída rede de água. }\end{array}$ \\
\hline 1990 & Canal de drenagem & $\begin{array}{l}\text { Em parceria com a ONG alemã GTZ, a ASMOCONP, após reuniões com moradores, executou } \\
1,7 \mathrm{~km} \text { de canal visando resolver problema de enchentes. Em 2014, a Prefeitura inicia obra de } \\
\text { novo canal. }\end{array}$ \\
\hline 1991 & $\begin{array}{l}\text { Seminário Habitando o } \\
\text { Inabitável }\end{array}$ & $\begin{array}{l}\text { Marco da história do conjunto que gera um pacto social entre as organizações populares para } \\
\text { dignidade do bairro. Ademais, dois frutos: criação da União das Associações e Grupos } \\
\text { Organizados do Conjunto Palmeira (UAGCONP) e o plano estratégico para urbanização. }\end{array}$ \\
\hline 1992 & $\begin{array}{l}\text { Plano de Desenvolvimento } \\
\text { Comunitário Integrado }\end{array}$ & $\begin{array}{l}\text { O PDCI foi construído pela comunidade para diagnósticos de problemas e diretrizes futuras. } \\
\text { Envolvia o esclarecimento e a participação ativa dos moradores em assuntos sociais (DST, } \\
\text { segurança, educação ambiental). }\end{array}$ \\
\hline 1992 & $\begin{array}{l}\text { Implantação da rede de } \\
\text { saneamento }\end{array}$ & $\begin{array}{l}\text { Mil moradores do Conjunto Palmeira na sede do Governo Estadual pressionando por } \\
\text { prioridade na implantação de um programa de saneamento, gritando palavras de ordem. Uma } \\
\text { comissão foi recebida para estabelecer conversações e, após embate, obtiveram êxito. }\end{array}$ \\
\hline 1997 & $\begin{array}{l}\text { Encontro de avaliação do } \\
\text { Seminário Habitando o } \\
\text { Inabitável }\end{array}$ & $\begin{array}{l}\text { Seis anos após o seminário, a comunidade concluiu que o bairro estava urbanizado, porém a } \\
\text { pobreza econômica impedia que muitos moradores que lutaram pela construção do bairro } \\
\text { pudessem continuar a morar nele devido os custos dessa urbanização. Necessidade de } \\
\text { geração de renda! }\end{array}$ \\
\hline $\begin{array}{l}1998 \text { a } \\
2002\end{array}$ & $\begin{array}{l}\text { Constituição do Banco Palmas } \\
\text { e criação da moeda social }\end{array}$ & $\begin{array}{l}\text { Organização produtiva social baseada em relações de solidariedade entre os moradores para } \\
\text { estimular a produção e o consumo no local. Nesse processo, foram criados instrumentos como } \\
\text { linhas de microcrédito, cartão de crédito e uso de uma moeda social circulante local, tudo } \\
\text { próprio e exclusivo da comunidade. }\end{array}$ \\
\hline 2003 & $\begin{array}{l}\text { Embate com Banco Central do } \\
\text { Brasil (BACEN) }\end{array}$ & $\begin{array}{l}\text { Banco Palmas foi acionado pelo Ministério Público (MP) a pedido do BACEN, pela criação da } \\
\text { moeda social Palmas. }\end{array}$ \\
\hline 2014 & Novo canal de drenagem & $\begin{array}{l}\text { Após quinze anos de reinvindicações, a Prefeitura inicia obras de novo canal de drenagem no } \\
\text { conjunto objetivando prevenção de enchentes. }\end{array}$ \\
\hline
\end{tabular}

Fontes: Compilado a partir de informações do Banco Palmas (2014), Melo Neto e Magalhães (2003a), Melo Neto e Magalhães (2003b), Melo Neto e Magalhães (2005), Instituto Palmas (2009), ASMOCONP (2012).

A criação do Banco comunitário, Banco Palmas, está no "bojo da evolução dessa luta". De acordo com um dos atores entrevistados, "a mesma estrutura de organização e mobilização social que a gente utiliza para as lutas sociais, utiliza também para a economia", ou seja, juntar as pessoas, organizar os moradores, criar produtos. "É a mesma conexão, a mesma liga, agora com abordagem mais para o financeiro, mas a base de fundamentação é a mesma" (Entrevista, Coordenador do Instituto Palmas, outubro de 2014). A experiência vai ao encontro da caracterização de economia solidária discutida por França Filho $(2004,2013)$, que ressalta que a extensão do fenômeno indica uma reconfiguração das relações entre o econômico, o social e o político.

Os projetos e empreendimentos de Economia Solidária ganharam força no Conjunto a partir da criação do Banco Palmas, idealizado após a avaliação do Seminário Habitando o Inabitável, em que a comunidade concluiu que era essencial buscar alternativas para o desenvolvimento econômico das famílias do bairro, que agora tinham que arcar com os custos da urbanização conquistada pelas lutas das mobilizações sociais. Nesse contexto, a ASMOCONP, o Banco Palmas e o Instituto Palmas potencializaram diversos projetos e empreendimentos solidários (Quadro 2) em parceria com outras organizações, todas norteadas por valores da economia solidária. Tais valores foram paulatinamente sendo compreendidos e compartilhados pelos moradores do conjunto. "Quando eu comecei a ouvir falar de economia solidária eu disse que de economia eu entendia porque eu acho que toda dona de casa entende. Ser solidário, eu também entendo. Mas juntando as duas palavras eu não entendo e quero que me expliquem. Assim uns vão entendendo, outros não" (Entrevista, Diretora Executiva da ASMOCONP, outubro de 2014).

Quanto ao embate com o BACEN, a mobilização teve um caráter sócio-ideológico. Acusados de crime por fazer circular uma segunda moeda em território nacional, representantes das organizações sociais do Conjunto elaboraram a defesa da moeda social junto ao Ministério Público fundamentados na relevância social e nos princípios de Economia Solidária. ASMOCONP/Banco Palmas prestaram esclarecimentos na Polícia Civil sobre o caráter 
Quadro 2 - Empreendimentos e Projetos Solidários no Conjunto Palmeira

\begin{tabular}{|l|l|}
\hline \multicolumn{1}{|c|}{$\begin{array}{c}\text { Projeto / Empreendimento } \\
\text { Solidário }\end{array}$} & \multicolumn{1}{c|}{ Descrição } \\
\hline PalmaFashion & Grupo produtivo de confecção, que trabalha principalmente com jeans. \\
\hline Palmart & Produção de artesanato que utilizava as técnicas de fuxico e estamparia. \\
\hline PalmaLimpe & $\begin{array}{l}\text { Microempresa que produz material de limpeza: detergentes, desinfetantes, amaciante, etc. Formada } \\
\text { por cinco jovens da comunidade. }\end{array}$ \\
\hline PalmaNatus & Fabricação de sabonetes artesanais e fitoterápicos. \\
\hline Bate Palmas & Grupo cultural, composto por jovens, para geração de renda por meio de atividades artísticas. \\
\hline PalmaTur & $\begin{array}{l}\text { Empreendimento, formado por mulheres, relacionado a turismo comunitário e prestação de serviços } \\
\text { em eventos. }\end{array}$ \\
\hline Loja Solidária & Espaço organizado para comercialização coletiva dos produtos fabricados. \\
\hline Feira de Produtores Locais & $\begin{array}{l}\text { Espaço público para comércio semanal de produtos feitos no Conjunto. Promove a cultura popular e } \\
\text { propicia encontro entre os moradores. }\end{array}$ \\
\hline Academia de Moda Periferia & Espaço de produção e formação profissional de jovens e mulheres, na área de moda. \\
\hline Bairro Escola de Trabalho & $\begin{array}{l}\text { Projeto de capacitação de jovens ao trabalho em que os capacitadores são os próprios } \\
\text { empreendimentos do bairro. Além disso, objetiva a criação de uma cultura de paz e capacidade de } \\
\text { luta. }\end{array}$ \\
\hline Incubadora Feminina & $\begin{array}{l}\text { Projeto de segurança alimentar junto a mulheres do bairro, objetivando possibilitar-Ihes cidadania e } \\
\text { renda por meio de cursos profissionalizantes, oficinas, laboratório de agricultura urbana, etc. }\end{array}$ \\
\hline Palmatech & $\begin{array}{l}\text { Escola encarregada pela gestão do conhecimento do Banco Palmas por meio da elaboração de } \\
\text { relatórios, materiais pedagógicos, oficinas e cursos de gestão, criação de rede e instrumentos de } \\
\text { Economia Solidária. }\end{array}$ \\
\hline Escola Popular Cooperativa Palmas & $\begin{array}{l}\text { Escola destinada à juventude com o objetivo de obtenção de sucesso no vestibular, desenvolvimento } \\
\text { da capacidade empreendedora, sensibilização para atividades comunitárias e proteção ambiental. }\end{array}$ \\
\hline
\end{tabular}

Fontes: Compilado a partir de informações do Banco Palmas (2014), Melo Neto e Magalhães (2003a), Melo Neto e Magalhães (2003b), Melo Neto e Magalhães (2005), Instituto Palmas (2009), ASMOCONP (2012).

Os empreendimentos produtivos da rede são pequenas unidades produtivas, formais e informais, financiadas pelo Banco Palmas, voltadas ao suprimento de demandas do bairro, articuladas em um sistema de rede. São independentes e interligadas por instrumento e regras de solidariedade do sistema Palmas, sendo acompanhadas diariamente pela equipe do banco (Banco Palmas, 2014).

A construção da identidade do Conjunto Palmeira associada à Economia Solidária é constatada pela existência dos projetos e empreendimentos apresentados no Quadro 2 e pelas características do Banco Palmas elencadas na memória do Instituto Palmas (2009): i) o banco não tem dono, é de propriedade coletiva, pertence à comunidade; ii) não se apropria de seus excedentes (lucro, na linguagem capitalista); iii) mantém taxas de juros abaixo do mercado; iv) estimula redes de colaboração entre produtores e consumidores; v) realiza análise de crédito com base no aval da vizinhança e confia na pessoa humana ao fazer a concessão do crédito. Tais características, alicerçadas na racionalidade substantiva, favorecem 0 processo de conscientização do ser cooperativo, enquanto uma identidade, conforme ressaltam Rocha-Pinto, Irigaray e Silva (2011).

A identidade do Conjunto Palmeira está em consonância também com as dimensões de Economia Solidária refletidas por França Filho (2013), expostas no referencial teórico deste artigo: a dimensão de fonte de renda, justificada pelos projetos e empreendimentos solidários (Quadro 2), e a dimensão de luta por direitos políticos, justificada pela sequência de mobilizações sociais (Quadro 1). Para a diretora executiva da ASMOCONP,

A economia solidária tem trazido melhorias para gerar de renda... Há mulheres que vêm de áreas de riscos, que saem da violência doméstica para formar grupos e aprenderem educação financeira, educação profissional, começam a trabalhar em sistema de cooperativismo na área de alimentação, de confecção (...).Algumas mulheres abandonadas pelos maridos, que dependiam do bolsafamília, passaram a ser pequenas empreendedoras e sustentar os filhos (Entrevista, Diretora Executiva da ASMOCONP, outubro de 2014).

Apesar das conquistas de urbanização e direitos sociais a partir das mobilizações e da inserção de milhares de pessoas na produção e no consumo local a partir dos projetos de economia solidária, o Conjunto Palmeira, em 2013, apresentou ser o bairro com menor renda média (menos de $\mathrm{R} \$ 250,00$ por pessoa) e menor Índice de Desenvolvimento Humano (IDH) da cidade de Fortaleza, conforme pesquisa realizada pela prefeitura. Esta capital, por sua vez, é a quinta cidade mais desigual do mundo (ONU, 2013). Em nota, a ASMOCONP ressalta que, embora o bairro tenha melhorado nos últimos anos, existe ainda um grande passivo social e graves problemas a serem resolvidos, oriundos de uma dívida social para com o bairro desde sua origem em 1973. Na nota, a organização ressalta outra constatação desse mesmo estudo: $75,7 \%$ dos bairros de Fortaleza têm baixa qualidade de vida. "O que indigna é a desigualdade, a brutal diferença entre as duas Fortalezas" (Asmoconp, 2013).

A partir da memória coletiva dos fatos históricos, a construção da identidade de mobilização e economia solidária no Conjunto Palmeira é reconhecida pelos moradores do local. Conforme coordenador do Instituto Palmas, "existe uma identidade de mobilização social e de economia solidária aqui. Eu acho que uma das características fortes do Palmeira é essa identidade que vem sendo trabalhada ao longo dos anos". Já a diretora executiva da ASMOCONP acredita tratar-se de "uma comunidade guerreira, de mobilização, de luta por melhorias, que se mobilizou nas áreas de trabalho, renda, inclusão social". Sendo assim, a construção de identidade se deu em reação às condições de pobreza pelas quais os moradores estavam expostos desde o momento que ali chegaram, fato que descreve um contexto de fonte de significado e de experiência de um povo, consonante com a definição de 
identidade discutida no referencial teórico deste estudo por Castells (1999).

4.2 - Mecanismos de Memória Organizacional que influenciaram a construção da identidade do Conjunto Palmeira

As análises de documentos e de conteúdo das entrevistas indicaram que os mecanismos de memória organizacional utilizados pelas organizações sociais para finalidades internas relacionadas à gestão são diferentes daqueles mecanismos adotados para exercer influência sobre o ambiente externo, especialmente a comunidade circundante, o Conjunto Palmeira, caracterizando esse caso como exceção perante as recorrentes visões gerencialistas pelas quais 0 assunto memória organizacional é abordado, conforme constatação de Rowlinson et al. (2010) e Costa e Saraiva (2011).

Na vertente do público interno, como ferramenta de gestão útil às situações de trabalho, a memória codificada do conhecimento organizacional está explícita em um "conjunto de ferramentas como planilhas, formulários, fichas e controles que facilitam o processo de gestão do banco comunitário. Essas ferramentas são bastante simples para permitir que a própria comunidade 'dê conta' de fazer a gestão sem grandes dificuldades" (Instituto Palmas, 2009, p. 14). Tais instrumentos são relevantes para o processo de autogestão tão caro às práticas em Economia Solidária. Além disso, a vinculação da memória organizacional com a aprendizagem organizacional mencionada na revisão teórica por Nonaka e Toyama (2008) e Santos et al. (2012), está presente no Banco Palmas por meio da utilização de documentos da memória organizacional na formação de indivíduos para situações de trabalho, principalmente "no curso de formação de longa duração (600 horas/aula) chamado Consultores Comunitários que capacita os moradores do bairro nas ferramentas e filosofias do Banco Palmas", fundamental à sustentabilidade do Banco (Instituto Palmas, 2009, p. 14).

Entretanto, a relevância da memória das organizações sociais não se limita às contingências internas. As organizações sociais do Conjunto Palmeira - ASMOCONP, Banco Palmas e Instituto Palmas - reconhecem a importância da memória organizacional para o fortalecimento da identidade do Conjunto Palmeira ao manter em suas instalações um "centro de documentação, um rico acervo de lutas - memórias vivas e resgatadas - de uma comunidade que ao longo dos anos conquistou sua urbanização, passando de uma sofrida favela para um bairro popular" (Melo Neto \& Magalhães, 2003a).

Quadro 3 - Memória de experiências e aprendizados

\begin{tabular}{|l|l|l|}
\hline \multicolumn{2}{|c|}{$\begin{array}{l}\text { EXPERIENCIA } \\
\text { RELATADA }\end{array}$} & \multicolumn{1}{|c|}{$\begin{array}{c}\text { APRENDIZADO } \\
\text { ADQUIRIDO } \\
\text { IÍ́NEIA } \\
\text { SITESE }\end{array}$} \\
\hline $\begin{array}{l}\text { "Os moradores que } \\
\text { durante 20 anos } \\
\text { lutaram pela } \\
\text { urbanização, não } \\
\text { podiam mais viver no } \\
\text { próprio bairro que } \\
\text { construíram". }\end{array}$ & $\begin{array}{l}\text { Não adianta urbanizar, } \\
\text { melhorar as condições de } \\
\text { moradia da favela, sem } \\
\text { que isso venha se juntar } \\
\text { a uma alternativa de } \\
\text { geração de renda. }\end{array}$ & $\begin{array}{l}\text { Busca por } \\
\text { melhores } \\
\text { condições de } \\
\text { vida deve ser } \\
\text { contínua. }\end{array}$ \\
$\begin{array}{l}\text { "Nosso atrevimento em } \\
\text { batizar o projeto de } \\
\text { Banco Palmas, }\end{array}$ & $\begin{array}{l}\text { Não se pode superar a } \\
\text { pobreza sem correr riscos } \\
\text { e sem ousadia. }\end{array}$ & $\begin{array}{l}\text { Toda } \\
\text { mudança } \\
\text { exige }\end{array}$ \\
\hline
\end{tabular}

\begin{tabular}{|c|c|c|}
\hline $\begin{array}{lr}\text { afirmando-o } & \text { como } \\
\text { banco dos excluídos } \\
\text { (...) fez com que } \\
\text { algumas portas se } \\
\text { abrissem". }\end{array}$ & & $\begin{array}{l}\text { coragem para } \\
\text { correr riscos. }\end{array}$ \\
\hline $\begin{array}{l}\text { "Estes [os moradores], } \\
\text { em sua maioria, } \\
\text { estavam 'fichados' no } \\
\text { SPC, SERASA e } \\
\text { CADIN [serviços de } \\
\text { proteção de crédito]". }\end{array}$ & $\begin{array}{l}\text { Para dar acesso a crédito } \\
\text { aos mais pobres, vizinhos } \\
\text { se constituem em um } \\
\text { verdadeiro e legítimo } \\
\text { SPC [Serviço de Proteção } \\
\text { ao Crédito] social. }\end{array}$ & $\begin{array}{l}\text { Construção da } \\
\text { confiança. }\end{array}$ \\
\hline $\begin{array}{lr}\text { "Em todo } & \text { momento } \\
\text { chegavam pessoas a } \\
\text { procura de uma } \\
\text { alternativa de vida. } \\
\text { Sabíamos } \\
\text { tínhamos que enfrentar } \\
\text { a situação com poucos } \\
\text { recursos financeiros e } \\
\text { materiais e com uma } \\
\text { equipe mínima de } \\
\text { trabalho". }\end{array}$ & $\begin{array}{l}\text { Somente a convivência } \\
\text { com as contradições } \\
\text { geradas pela extrema } \\
\text { exclusão é capaz de } \\
\text { possibilitar conhecimento } \\
\text { e sabedoria para fazer a } \\
\text { mais desafiadora de } \\
\text { todas as gestões: a } \\
\text { gestão da pobreza. }\end{array}$ & $\begin{array}{l}\text { "Ninguém } \\
\text { supera a } \\
\text { pobreza } \\
\text { sozinho" (Paul } \\
\text { Singer). }\end{array}$ \\
\hline $\begin{array}{lr}\text { "Fizemos } & \text { um } \\
\text { mapeamento } & \text { de } \\
\text { produção e consumo. } \\
\text { Dos R\$ } 1.540 .241,88 \\
\text { gastos pelas } \\
\text { mensamenilias } \\
1.015 .000,00, & \text { R } \$ \\
\text { gastos } & \text { coram } \\
\text { alimentação". } & \end{array}$ & $\begin{array}{l}\text { A produção local deve ser } \\
\text { focada para a área } \\
\text { alimentícia, pois é } \\
\text { prioridade de consumo } \\
\text { em bairro popular. }\end{array}$ & $\begin{array}{l}\text { Organização } \\
\text { da oferta. }\end{array}$ \\
\hline $\begin{array}{l}\text { "Foram } 45 \text { Reuniões } \\
\text { com produtores, } \\
\text { comerciantes e sócios } \\
\text { da ASMOCONP (...) } \\
\text { mais problemático que } \\
\text { não ter como investir } \\
\text { era não ter como } \\
\text { comercializar seus } \\
\text { produtos". }\end{array}$ & $\begin{array}{l}\text { O primeiro passo para } \\
\text { enfrentar o problema da } \\
\text { geração de renda em um } \\
\text { bairro popular não é } \\
\text { investir na produção, e } \\
\text { sim, organizar os } \\
\text { consumidores. }\end{array}$ & $\begin{array}{l}\text { ização } \\
\text { nanda. }\end{array}$ \\
\hline 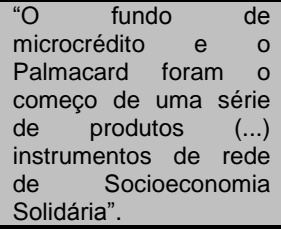 & $\begin{array}{l}\text { O microcrédito, quando } \\
\text { concedido isoladamente e } \\
\text { dentro de uma lógica de } \\
\text { concorrência capitalista, } \\
\text { normalmente, leva o } \\
\text { tomador para uma } \\
\text { situação pior. }\end{array}$ & $\begin{array}{l}\text { Crédito deve } \\
\text { ser um } \\
\text { mecanismo de } \\
\text { emancipação. }\end{array}$ \\
\hline $\begin{array}{lr}\text { “Um número } \\
\text { considerável } \\
\text { pessoas procurava o } \\
\text { Banco Palmas em } \\
\text { busca de ajuda para } \\
\text { comer ou comprar } \\
\text { remédios (..) tão } \\
\text { debilitadas que já não } \\
\text { vislumbravam } \\
\text { possibilidade gerir seu } \\
\text { próprio sustento". }\end{array}$ & $\begin{array}{l}\text { Projetos de } \\
\text { desenvolvimento local em } \\
\text { bairros pobres precisam } \\
\text { ter a preocupação de } \\
\text { como envolver as famílias } \\
\text { que estão na linha da } \\
\text { miséria, sem condições } \\
\text { mínimas de participação } \\
\text { cidadã. }\end{array}$ & $\begin{array}{l}\text { Construção } \\
\text { contínua do } \\
\text { sentido de } \\
\text { comunidade. }\end{array}$ \\
\hline $\begin{array}{l}\text { "Muito se fala dos } \\
\text { bairros populares } \\
\text { naquilo que ele tem de } \\
\text { feio, de problemático, } \\
\text { de triste. Raramente os } \\
\text { pobres rão } \\
\text { reconhecidos como } \\
\text { portadores de solução!" }\end{array}$ & $\begin{array}{l}\text { É preciso divulgar o que } \\
\text { se faz de bom para } \\
\text { compensar um pouco a } \\
\text { imagem negativa dos } \\
\text { bairros pobres que está } \\
\text { no senso comum. }\end{array}$ & $\begin{array}{l}\text { Superação de } \\
\text { estigmas via } \\
\text { comunicação. }\end{array}$ \\
\hline $\begin{array}{l}\text { "Dificilmente o Banco } \\
\text { Palmas funcionaria na } \\
\text { sua atual plenitude de } \\
\text { ações dentro de um } \\
\text { marco legal [do } \\
\text { Sistema Financeiro } \\
\text { Nacional] rasil". } \\
\text { existente no Brasil" hoje }\end{array}$ & $\begin{array}{l}\text { Não se pode mudar as } \\
\text { ações, mudar missão } \\
\text { para adaptar-se às regras } \\
\text { e à legislação vigente. } \\
\text { São as leis que precisam } \\
\text { adaptar-se às exigências } \\
\text { da realidade. }\end{array}$ & $\begin{array}{l}\text { Mudar a } \\
\text { realidade para } \\
\text { mudar as leis. }\end{array}$ \\
\hline $\begin{array}{l}\text { "No início a relação } \\
\text { com o poder público foi } \\
\text { muito difícil (...). A } \\
\text { estratégia consistiu em } \\
\text { ir conquistando espaço } \\
\text { propondo pequenos } \\
\text { apoios pontuais. O } \\
\text { importante era garantir } \\
\text { a presença do poder } \\
\text { público". }\end{array}$ & $\begin{array}{l}\text { A associação de } \\
\text { moradores deve } \\
\text { participar, fazer sua parte } \\
\text { (...), mas jamais deixar de } \\
\text { lutar por políticas públicas } \\
\text { como instrumento } \\
\text { indispensável para } \\
\text { superação da pobreza de } \\
\text { forma sustentável. }\end{array}$ & $\begin{array}{lr}\text { Organização } \\
\text { social } & \text { para } \\
\text { superar } & \text { a } \\
\text { pobreza. } & \end{array}$ \\
\hline
\end{tabular}

Fonte: Elaborado a partir das análises de Melo Neto e Magalhães (2003a)

Experiências e aprendizados foram registrados em livros, vídeos, cartilhas, maquetes, atas de reuniões, relatórios, planilhas, 
fotos, cordéis, roteiros de peça de teatro, panfletos, fotonovelas, objetos históricos, dentre outros mecanismos que foram sendo produzidos pelas próprias organizações (formadas por moradores do Conjunto Palmeira), a partir da ocorrência das experiências comunitárias relatadas. A produção e o uso desses registros caracterizam, segundo Misztal (2003) e Rowlinson, et al. (2010), uma memória social a partir de manifestações organizacionais.

O principal mecanismo de codificação dessa memória, como identificado nas entrevistas, é uma "série que é chamada Memória de Nossas Lutas. Conjunto de cartilhas cuja forma editorial é muito simples: são as pessoas dando depoimentos. São coletadas fotos e é feita a cartilha" (Entrevista, Coordenador do Instituto Palmas, outubro de 2014).

O coordenador do Instituto Palmas destaca que as ferramentas de linguagem mais populares, tais como cordéis e fotonovelas, exercem maior efeito pedagógico. Contudo, também ressalta a importância do uso de novas tecnologias.

A valorização da memória das organizações sociais do Conjunto Palmeira não se limita ao registro das experiências vividas, mas alcança uma estruturação de aprendizados adquiridos a partir dessas experiências no intuito utilizá-los em novos contextos sociais e econômicos do bairro. No Quadro 3 estão organizadas onze lições ou aprendizados adquiridos a partir das experiências vividas ao longo da história do Conjunto Palmeira e dos processos de organização e gestão das organizações sociais criadas.

Ressalta-se que a estruturação desses aprendizados também é frequentemente utilizada para orientar outras organizações sociais que almejam implantar projetos de desenvolvimento econômico e social semelhantes em outros locais do Brasil. Esse fortalecimento associativo e de enlaces colaborativos interorganizacionais caracteriza a finalidade de organizações sociais, conforme argumentação de Britton (2005) refletida na revisão teórica.

4.3 - Efeitos da memória das organizações sociais sobre o fortalecimento da identidade local

A relevância da memória organizacional dessas organizações sociais extrapola sua utilidade como ferramenta interna de gestão e se configura também como um instrumento valoroso para construção da identidade de mobilização social e economia solidária do bairro. Para o coordenador do Instituto Palmas, "são três fatores muito importantes para o sucesso: a identidade, a memória e a autonomia. (...) Se você não conhece a história, não cria essa identidade, não cria essa memória, você não valoriza. Mais precisamente, a memória é tratada como mecanismo utilizado para a comunidade aderir aos projetos de mobilização social, pois há muitos anos existe no Conjunto Palmeira um trabalho realizado pela ASMOCONP que "resgata a memória do bairro, registrando o nosso passado, as lutas para construir o bairro, as conquistas da comunidade. Essa memória fez com que as pessoas criassem identidade com o bairro" (Instituto Palmas, 2009, p. 8).
A memória organizacional estimulou nova luta social a partir do relato de conquistas passadas. Em 1988 ocorreu a mais destacada mobilização social da história do Conjunto Palmeira: a luta pelo abastecimento de água. O fato que chama atenção é que, um ano antes, houve a participação ativa da comunidade no programa Memória de Nossas Lutas, que inflamou a memória de lutas e conquistas dos moradores do Palmeira, consequentemente exercendo influência motivadora sobre a histórica mobilização social que aconteceria no ano seguinte. "Eu não tenho dúvidas que houve influência. A identidade e a memória dão uma coisa chamada poder, poder local. Então, a luta da água, todas as lutas foram influenciadas porque o povo aprendeu a lutar. Essas memórias impulsionam a luta" (Entrevista, Coordenador do Instituto Palmas, outubro de 2014). "Acredito que houve influência, sim. Alimentou mais dentro das pessoas o sentimento de lutar por melhorias. Registrar a memória valeu a pena!" (Entrevista, Diretora Executiva da ASMOCONP, outubro de 2014). Essas afirmações reforçam o entendimento de Bonilha e Sachuk (2011) sobre a identidade como um fenômeno dinâmico, feito sempre com a integração entre elementos do presente e do passado, gerando continuidade.

As experiências e aprendizados (Quadro 3) auxiliam nas tomadas de decisões nas reuniões de interesse coletivo no bairro. "Às vezes, nas reuniões, para tomar decisões usamos a memória para ver se podemos utilizar alguma experiência do passado para resolver." (Entrevista, Diretora Executiva da ASMOCONP, outubro de 2014).

A memória organizacional também é um importante mecanismo de comunicação com os moradores do Conjunto Palmeira no que diz respeito à identidade de Economia Solidária, estimulando o envolvimento junto a empreendimentos solidários locais e a importância do consumo no bairro como estratégia de fortalecimento da moeda social. "Quando o Banco Palmas foi criado mostramos, através de uma comunicação adequada (vídeos, cartilhas, cordéis, fotonovelas, programas de rádio comunitária), como o projeto seria capaz de melhorar a vida das pessoas e da comunidade" (Instituto Palmas, 2009, p. 12). Tais comunicações vão ao encontro das ideias expostas na reflexão teórica realizada por Braga, Henriques e Mafra (2007) e Cruz e Silva (2013) que ressaltam a importância da comunicação nas mobilizações sociais visando a participação dialógica de sujeitos ativos que buscam problematizar com o outro para melhor compreender, explicar e transformar a realidade.

Apesar do reconhecimento da identidade local, existem pessoas no Conjunto que desconhecem ou não participam do projeto solidário, especialmente devido ao crescimento populacional do bairro que já abriga mais de 35 mil moradores em suas ruas urbanizadas. "São pessoas de vários lugares, que chegam e que partem. Tem gente que diz que não conhece o banco, ou pensa que é uma enganação de lideranças comunitárias. O importante é que muita gente acredita, participa e valoriza" (Instituto Palmas, 2009, p. 15).

Desse modo, a memória das organizações sociais do Conjunto Palmeira tem um constante desafio socioeducativo junto 
aos moradores do bairro. "A gente tem livros, atas de assembleias, vídeos tentando sempre resgatar a história passando para os moradores e para os alunos das escolas que vêm pesquisar sobre o bairro. A gente tá com um projeto de premiar nas escolas alunos que façam trabalhos sobre o Conjunto Palmeira" (Entrevista, Diretora Executiva da ASMOCONP, outubro de 2014). Ressaltamse também os usos de peças de teatro, fotonovela, cordéis, panfletos, pinturas de muro, rádio local, músicas temáticas; toda essa memória já foi utilizada como instrumento de comunicação dos valores da identidade local no intuito de construir base para transformação e fomentar a discussão de cunho educativo pedagógico, em congruência com a afirmação de Cruz e Silva (2013). Percebe-se uma preocupação da comunidade para a transmissão dos valores construídos socialmente para gerações futuras. Segundo a diretora da ASMOCOMP, "hoje temos jovens que não viveram aquele início do Palmeira, foram formados também por essa memória, são sócios e podem ser futuros diretores executivos porque estão inseridos dentro dessa história".

Como desafio futuro, há o projeto de criação do museu do bairro que, segundo Coordenador do Instituto Palmas, poderá ser interativo com salas de projeção, com espaços onde seja possível expor materiais, pergaminhos, livros, etc. O aperfeiçoamento da memória organizacional está presente dentre os desafios do Banco Palmas até o ano de 2019: "reorganizar de forma ampla e consistente nosso [do Banco Palmas] centro de documentação e memória e criar um centro de referência em finanças solidárias que, em médio prazo, avance para uma universidade popular" (Instituto Palmas, 2009, p. 18). Tal relato demonstra, também em planejamentos futuros, ousadia e valorização da sua memória.

Como visto, a memória organizacional, para Simão (2010) e Choo (2006), deve permitir que se responda a questões tanto sobre a organização como também sobre seu ambiente, ou seja, tanto para seu público interno quanto para os atores externos, tais como clientes e cidadãos. Nesse sentido, a memória organizacional da ASMOCONP, Banco Palmas e Instituto Palmas parece poder ser compreendida através da ideia de memória organizacional estudada na literatura.

Por fim, ressalta-se que a utilização da memória das organizações sociais exerce influência sobre o ambiente externo para além da comunidade circundante. Experiências e aprendizados (Quadro 3) foram codificados pelo Banco Palmas em uma cartilha de sistematização que tem a finalidade de expansão de bancos comunitários. Muitas instituições aprenderam com o método do Banco Palmas e estão reaplicando em outras cidades brasileiras. A cartilha funciona como medida protetora dos princípios, valores e originalidade da proposta (Instituto Palmas, 2009). Até 2013, outros 102 bancos comunitários iniciaram suas atividades no Brasil estimulados pela experiência do precursor Banco Palmas e, muitos deles, especialmente os localizados na região nordeste, orientados e incubados pelo Instituto Palmas. Há uma busca por um marco legal específico para a moeda circulante local no Brasil. "Acreditamos, inclusive, que a leitura desta publicação irá engrossar as fileiras de brasileiras e brasileiros que esperam ver ações desta natureza além de, amparadas pela lei, incorporadas como políticas públicas de inclusão social e massificadas em todo território nacional" (Melo Neto; Magalhães, 2005, p. 54), explicitando a relevância da memória organizacional também em um sentido macro, de legislação e sociedade.

\section{Considerações Finais}

Este estudo propôs analisar a influência da memória organizacional na construção e na continuidade da identidade do Conjunto Palmeira, em Fortaleza, Ceará. Uma imersão na história sociocultural do bairro possibilitou a identificação de ações, mobilizações e projetos que protagonizaram contextos de lutas por direitos sociais e por geração renda, bem como possibilitou auferir respostas para questionamentos acerca de origens, datas, fatos e motivos que influenciaram a construção da identidade local associada às mobilizações sociais e à economia solidária. Identidade que foi fortalecida por meio de mecanismos da memória das organizações sociais pesquisadas.

A realização do referido objetivo trouxe para a literatura sobre Memória Organizacional contribuições no que diz respeito à sua influência sobre a memória social e a identidade local. O foco sobre o ambiente externo possibilitou a identificação de mecanismos e efeitos diferentes daqueles adotados para objetivos internos, gerencialistas.

Visando exercer influência sobre o ambiente externo, experiências e aprendizados foram registrados na Memória Organizacional por meio de livros, vídeos, cartilhas, maquetes, atas de reuniões, relatórios, planilhas, fotos, cordéis, roteiros de peças de teatro, panfletos, fotonovelas, objetos históricos, dentre outros. Tais documentos e objetos, pertencentes à memória das organizações sociais, se configuram como mecanismos de memória utilizados para a comunidade aderir aos projetos de mobilização social e aos empreendimentos econômicos solidários, tidos como identitários do local. Frequentemente, esses mecanismos são utilizados em reuniões comunitárias, em visitações escolares, em eventos festivos, em campanhas sociais e em cursos destinados à comunidade. Destacam-se o livro/cartilha "Memórias de Nossas Lutas", as novas tecnologias e os mecanismos de linguagem mais popular, como cordéis e fotonovelas, que exercem maiores efeitos pedagógicos sobre a comunidade.

Os efeitos da utilização da memória das organizações sobre a memória social e sobre a identidade local são percebidos quando: o resgate de conquistas sociais passadas estimula novas lutas e fortalecem aspectos sócio-políticos; tomadas de decisões em reuniões comunitárias são orientadas pelos registros de experiências anteriores; informações, conhecimentos e valores são compartilhados na comunidade; campanhas socioeducativas envolvem os moradores em torno de um objetivo comum; roteiros de eventos artísticos possibilitam o envolvimento de moradores 
em situações de convivência e compartilhamentos; novos empreendimentos solidários são estimulados a partir de experiências anteriores bem-sucedidas e codificadas; hábitos de consumo no bairro são estimulados, fortalecendo a moeda solidária adotada e, consequentemente, a economia local.

Constata-se que a história do Conjunto Palmeira, registrada e compartilhada pela memória das organizações sociais, apresenta uma identidade política, pois são identificados: pertença, valores, crenças e histórias coletivas comuns; relações - de caráter opressor - com o poder público e com o poder do capital; embates na luta por espaços, mediante antagonismos.

Além da influência junto à identidade local, a memória das organizações sociais é útil como mecanismo gerencial que facilita procedimentos em situações de trabalho, possibilitando a gestão comunitária. Assim como também é valoroso na aprendizagem de valores, procedimentos e práticas de novos colaboradores em seu processo formativo de longa duração.

A memória organizacional influencia positivamente também na proposta de reaplicação dos projetos e experiências vividas no Conjunto Palmeira em outros contextos de desenvolvimento local. Livros, vídeos e cartilhas que registram o conhecimento organizacional possibilitam que a ASMOCONP e o Banco Palmas sejam espelhos para outras experiências e que o Instituto Palmas seja agente de incubação de dezenas de outros bancos comunitários no Brasil, especialmente no nordeste.

Esta pesquisa aponta para a relevância de aprofundamentos nestas discussões. Dois destes caminhos são a sua própria continuidade e o empreendimento de uma próxima etapa de levantamento e análise de informações dentre os moradores de modo geral. Algumas questões podem guiar a pesquisa nesta direção: como estes moradores recém-chegados no bairro vêm se apropriando da sua história e das suas formas de participação popular e de organização social? Como outras organizações sociais atuam na construção da identidade local e como se manifesta sua memória organizacional neste processo?

\section{Referências}

Abreu, M. C. S., Lima, B. C. C., Silva, V. M. M., \& Cunha, L. T. (2013). O exercício da cidadania corporativa contribuindo para a transformação da realidade social da comunidade Serviluz. Revista Brasileira de Estratégia, 6(2), 165-177

ASMOCONP (2012). História da ASMOCONP. Instituto Palmas.

Beuron, T. A., Matos, R. D. D., Barros, A. S. D., \& Grohmann, M. Z. (2011). Trabalho, Poder e Identidade: o Caso de uma Associação Autogestionária Familiar de Produção Agrícola. Revista ADM. MADE, 15(2), 63-81.

Bonilha, M. C., \& Sachuk, M. I. (2011). Identidade e tecnologia social: um estudo junto às artesãs da Vila Rural Esperança. Cadernos EBAPE. $B R, 9(2), 415-37$.

Braga, C. S.; Henriques, M. S.; Mafra, R. L. M. (2007). Comunicação e estratégias de mobilização social. Autêntica.

Britto, B. (2005). Aprendizaje organizacional en ONG: creando el motivo, los medios y la oportunidad. Documento Praxis, (3), 1-73.

Castells, M. (1999). O poder da identidade (vol II). A Construção da identidade, 22-28.

Choo, C. W. (2003). Gestão de Informação para a Organização Inteligente a arte de explorar o meio ambiente. Lisboa: Editorial Caminho.

Costa, A. D. S. M., \& Saraiva, L. A. S. (2011). Memória e formalização social do passado nas organizações. Revista de Administração Pública,45(6), 1761-1780.

Cruz, K. A. V. M., \& Silva, W. A. C. (2013). O Papel da Comunicação e da Mobilização em Projetos Públicos: Análise do Projeto Cidade Eficiente (Eló Mendes-MG). Desenvolvimento em Questão, 11(22), 62-94.
Donders, Y. (2005). Para um direito à identidade cultural na legislação internacional dos direitos humanos. MA Serra, Diversidade cultural $e$ desenvolvimento urbano. São Paulo: Iluminuras.

Erll, A., Nünning, A., \& Young, S. B. (Eds.). (2008). Cultural memory studies: An international and interdisciplinary handbook (Vol. 8). de Gruyter.

Ferreira, M. P., Pinto, C. F., Santos, J. C., \& Serra, F. A. R. (2013). Ambiguity and the implications for the future of ethical behavior: an intercultural study. Revista de Administração de Empresas, 53(2), 169-182.

França Filho, G. C. (2013). A problemática da economia solidária: um novo modo de gestão pública? Cadernos EBAPE. BR, 11(3), 443-461.

Gattai, S., \& Bernardes, M. A. (2013). O Papel e Responsabilidades da Universidade no Processo Socioeducativo Presente em Movimentos de Economia Solidária. Revista de Administração Mackenzie, 14(6).

Geertz, C. (1989). A religião como sistema cultural. $A$ interpretação das culturas, 2.

Halbwachs, M. (1990). A memória coletiva (1950). Trad. Beatriz Sidou, São Paulo.

Hall, S. (2003). A identidade cultural na pós-modernidade; trad. Tomaz Tadeu da Silva e Guacira Lopes Louro. $7^{a}$ ed. Rio de Janeiro: DP\&A

Henriques, M. S., Braga, C. S., Couto e Silva, D., \& Mafra, R. (2007) Relações Públicas em projetos de mobilização social: funções $e$ características. Comunicação e estratégias de mobilização social, 2.

Palmas, B. A. N. C. O. (2009). 100 PERGUNTAS Mais Frequentes. Fortaleza: Instituto Palmas.

Lavandoski, J., Tonini, H., \& Barretto, M. (2012). Uva, vinho e identidade cultural na Serra Gaúcha (RS, Brasil). Revista Brasileira de Pesquisa em Turismo, 6(2), 216-232.

Medeiros, A. C., \& da Cunha, E. V. (2012). Economia Solidária e Desenvolvimento Local: A Prática dos Empreendimentos Econômicos Solidários na Região do Cariri Cearense. Desenvolvimento em Questão,10(21), 61-87.

Melo Neto, M. N., Joaquim, J., \& Magalhães, S. (2003a). Banco Palmas ponto a ponto.

Melo Neto, João J. M; Magalhães, S. (2003)._(Org.) PLIES: Plano Local de Investimento Estratégico-uma metodologia para gerar trabalho em territórios de baixa renda. Fortaleza: Instituto Banco Palmas.

Melo Neto, João J. M; Magalhães, S. (2005). O poder do circulante local. A moeda social no Conjunto Palmeira. Fortaleza: Instituto Banco Palmas

Misztal, B. (2003). Theories of social remembering. McGraw-Hill Education.

Molina, L. G., \& Valentim, M. L. P. (2011). Memória organizacional, memória corporativa e memória institucional: discussões conceituais e terminológicas. Revista EDICIC, 262-276.

Nonaka, I., \& Toyama, R. (2008). Criação do conhecimento como processo sintetizador. NONAKA, I.; TAKEUCHI, H. Gestão do conhecimento. Tradução de Ana Thorell. Porto Alegre: Bookman, 90-117.

Nilakanta et al., 2006

Oliveira, F. (2001). Aproximações ao enigma: o que quer dizer desenvolvimento local?. Pólis.

Pimentel, T. D., \& Carrieri, A. D. P. (2011). A espacialidade na construção da identidade. Cadernos EBAPE. Br, 9(1), 1-21.

Prado, M. A. M. (2002). Da mobilidade social à constituição da identidade política: reflexões em torno dos aspectos psicossociais das ações coletivas. Psicologia em revista, 8(11), 59-71.

Richardson, R. J. (2008). Pesquisa Social: métodos e técnicas (3 ed. rev. amp.) São Paulo: Atlas.

Rocha-Pinto, S. R., Irigaray, H. A. R.; SILVA, R. C.F. Tu me ensina a faze renda", eu te ensino a trabalhar: a organização do trabalho de uma cooperativa popular. Revista de Gestão (REGE), 18 (1), 35-51.

Rowlinson, M., Booth, C., Clark, P., Delahaye, A., \& Procter, S. (2009). Social remembering and organizational memory. Organization Studies. 31(01), 69-87

Rowlinson, M., Hassard, J., \& Decker, S. (2014). Research strategies for organizational history: A dialogue between historical theory and organization theory. Academy of Management Review, 39(3), 250-274.

Santos, J. L.S.; Maldonado, M. U.; Santos, R. M. N.; Steil, A. V. (2011) Perfil das pesquisas acadêmico-científicas sobre memória organizacional. Espacios, 39, (12), 12-26.

Simão, H. E. (2010) Memória organizacional..Acesssado em Fevereiro 24 2014

$<$ www.batebyte.pr.gov.br/modules/conteudo/conteudo.php?conteudo=1716 $>$

Silva Júnior, J. T.. (2004). Gestão, fato associativo e economia solidária: a experiência da ASMOCONP/Banco Palmas. Dissertação de mestrado, Escola de Administração, Universidade Federal da Bahia, Salvador, Brasil.

Singer, P.; Souza, A. R. (2002). A economia solidária no Brasil: a autogestão como resposta ao desemprego. Contexto.

Souza, M. M., \& Carrieri, A. D. P. (2012). Identidades, práticas discursivas e os estudos organizacionais: uma proposta teórico-metodológica. Cadernos Ebape. BR, 10(1), 40-64. 
Stein, E. W. (1995). Organization memory: Review of concepts and recommendations for management. International Journal of Information Management, 15(1), 17-32.

Strauss, A. L. (1999). Espelhos e máscaras: A busca de identidade. São Paulo: Edusp.

Walsh, J. P., \& Ungson, G. R. (1991). Organizational memory. Academy of management review, 16(1), 57-91.
Zancanaro, A. Erpen, J. G., Santos, J. L. S., Steil, A. V., \& Todesco, J. L. (2013). Mapeamento da produção científica sobre memória organizacional e ontologias. Perspectivas em Ciência da Informação, 18(1), 43-65.

Zerubavel, E. (2012). Time maps: Collective memory and the social shape of the past. University of Chicago Press. 